eye, the other had been lost after a cataract operation about ten years earlier. This case was a typical one in which not to operate. The cataract was hypermature, of a very nasty colour, with capsular thickenings. The iris was muddy and atrophic, posterior synechiae were present. We could not find any precipitates and the projection of light was very poor. In spite of the prayers of his doctor and himself to do something we refused to have anything to do with it.

\title{
FACULTY OF OPHTHALMOLOGISTS
}

\section{Report of Council Meeting on January 9, 1948}

THE report of the Joint Sub-Committee of the B.M.A. Ophthalmic Group Committee and the Faculty on the Future of the National Ophthalmic Treatment Board was discussed. The Council agreed that the continuation of the N.O.T.B. in the Supplementary Service should be supported and approved the report except in so far as they did not feel it was advisable that the N.O.T.B. should infiltrate into hospitals and use hospital clinics as premises if these premises could be used for clinics under the Permanent Service.

A memorandum on the Ideal School Ophthalmic Service, prepared for the Ophthalmic Group Committee by Mr. Black and Mr. Mackie, was approved with minor amendments.

The Council approved the memorandum on "Ophthalmology in Industry : a pilot experiment," prepared by Mr. Duthie, which it was proposed to carry out in Manchester in association with the University of Manchester and the Eye Hospital.

With regard to the study visits to clinics abroad, the Council agreed that the selection of applicants should be left to the discretion of the Sub-Committee, but suggested that preference should be given to junior Members, of the status of assistant surgeon.

A query as to what conferred on Orthoptists the right to practise had been referred to the British Medical Association, who had replied saying that if an Orthoptist transgressed rules, ethical or otherwise, which, in the opinion of one or all of the sponsoring bodies made it undesirable for her to practise under their aegis, the body whose rules had been infringed was the body to expel the offender from membership, and that expulsion by the Orthoptic Board would carry with it deletion from the Register of Medical Auxiliaries.

It was reported that an objection to the increased fee of 2 guineas, 
which was now operating where insured persons were referred by ophthalmic opticians to ophthalmic surgeons, while at the same time ophthalmic surgeons were prepared to see insured patients sent direct by the Approved Society for a fee of 1 guinea, had been referred to the B.M.A. Ophthalmic Group "Committee, who had reaffirmed its opinion that the increase should be made. This was endorsed by the Council.

The following resolutions put forward by the Medical Staffs and Matrons of the Ophthalmic Hospitals regarding the Working Yarty Report on the Recruitment and Training of Nurses were approved:-

(a) Ophthalmic nursing should be acknowledged as a specialty. It should not be considered part of the training for general surgery but should be carried out in a separate unit or complete department controlled by a specially trained sister, or in her absence, by a specially trained staff nurse.

(b) Nurses desiring to specialise in this work should be sent to an ophthalmic hospital where possible, otherwise to the eye unit in a general hospital for their intensive training, to be followed (if they still wish to continue in this branch), by one year as a staff nurse under supervision.

It was agreed to recommend that the ophthalmic hospitals should continue to be able to recruit applicants to nursing at an age earlier than 18. The Honorary Secretary was requested to forward these resolutions to the Ministry of Health, communicating the Council's agreement and support.

The B.M.A. Ophthalmic Group Committee's recommendation that, pending the examination, agreement and approval of curricula by the representative bodies of the profession and opticians, medical practitioners should take no part in the instruction or examination of opticians or student opticians in clinical ophthalmology, was approved.

A request had been received from the National Institute for the Blind for copies of technical periodicals to be sent to ophthalmologists in the British Zone of Germany. The Honorary Secretary was instructed to draw special attention to this in this summary of the Council minutes in the Medical Press, asking ophthalmologists to send any periodicals they could spare to the National Institute for the Blind, 224-6-8 Great Portland Street, London, W.1. 